\title{
An Experimental Study on the Possibility of Demolition of Destroyed Concrete Buildings with Different Types of Acid
}

\author{
AYMEN AWAD ${ }^{1, *}$, FERAS AL ADDAY ${ }^{2}$, ALTAYEB QASEM ${ }^{3}$, ALI AL-DULAIMY ${ }^{4}$ \\ ${ }^{1}$ Middle East University, Amman, Jordan. \\ ${ }^{2}$ Middle East University, Amman, Jordan. \\ ${ }^{3}$ Imam Abdulrahman Bin Faisal University, Saudi Aribia. \\ ${ }^{4}$ Ali Al-Dulaimy. \\ (*Corresponding Author (Aymen Awad). ORCID: 0000-0002-1862-2452)
}

\begin{abstract}
With the increase of environmental damage, especially in the Arab region as a result of wars in the past years and the destruction of infrastructure, engineers are concentrating more on reducing adverse environmental influences. In this study, the effect of three types of acids on the concrete properties, the corrosion progresses, chemical reaction rate and the penetration of the acid to the concrete were tested. The types of acids used in this research are Nitric, Sulfuric and Hydrochloric acids. It has been adopted to make holes in concrete cubes before submerging them with acid solutions to determine the penetration and chemical reaction rate by observation, all the solutions where ready to be poured in the holes using 2 cubes of concrete for each of the 8 solution which have different concentrations of acids. The results indicated that the rate of chemical reactions are not the same for the acids which they have different concentrations. The Nitric acid is more corrosive and reactive since the concrete absorbed $100 \mathrm{~mL}$ in 330 minutes through a contact area of 23 $\mathrm{cm} 2$. Nitric acid have reduced the compression strength by $37 \%$ and the mass loss is $21 \%$.
\end{abstract}

Keywords: Acids Attack, Nitric, Hydrochloric, Sulfuric, Chemical reaction

\section{INTRODUCTION}

Urban and industrial developments in recent decades have been accompanied by significant increases in the need to demolish old buildings [Koushkbaghi, 2019]. In addition, catastrophes, wars, and earthquake are the reasons that make the demolition is inevitable. Demolition can be defined as the dismantling; de-construction; wrecking; knocking; cutting or pulling down of any structure, building, plant, edifice [Dbpgdnz, 2019, Al Adday, 2019]. Demolition waste as well as construction waste constitutes the largest volume of municipal waste requiring high transportation and landfill running costs [Sallal R. Abid., 2018; Najib N. Gerges.2018]. Statistics indicate that developed countries suffer from spending big budgets on the maintenance, repair and demolition of infrastructure, Where spending up to $50 \%$ in the EU, and $35-45 \%$ in UK [Gardner, 2018]. The large budgets in this field are due to the desire of human to search to meet his basic needs in the new housing that is less expensive and better environmentally[ Arowojolu, 2019]. However, one of the challenges facing the civil engineer is the choice of demolition process. For example, old processes, the structure was typically dismantled by manual hammer [Parnav, 2015]. Demolition of buildings in the traditional process (pulling down a building with a backhoe) often produce noise, dust, undesirable vibrations of adjacent buildings and water pollution. For the modern technology which relied on the dismantling of the construction parts in a manner that is contrary to the stages of construction and thus can reduce the environmental damage, this method called a deconstruction or green demolition [Schultmann, 2008]. On the other hand, there are several other methods of demolition, from blasting methods, ball and crane, pusher arm, deliberate collapse, wire pulling, to a hydrodemolition [Anumba et al, 2003; Aazdak, 2008; Awad, 2020]. Green demolition procedure has more time and higher budget than conventional demolition [Bradley and Timothy, 2018]. But, these methods have several advantage, including recover waste materials for recycling, the ecological health of the community, and a safe work environment [Usman et al, 2013]. Concrete is used in bridges, rigid pavement, dams, residential buildings and so on. Concrete is a combination of paste and coarse, fine, and filler aggregates, where the water and Portland cement make up the paste. Hydration is the process by which cement reacts chemically, the paste toughens and increases strength to create a solid body known as concrete [PCA, 2002, Fatima Alsaleh, 2019]. But after casting the concrete, it is necessary to curing, it is necessary to complete internal reactions in cement paste [Saffar., 2019, Al Adday \& Awad, 2019]. Concrete have been used broadly in construction engineering because of its long durability, low cost, and high strength [Saleh A, 2015, Al Adday, 2020]. With these benefits, however, it has its most significant weaknesses, such as low tensile resistance, shrinkage and subsequent cracks, low resistance for fire, particularly at temperatures above $500{ }^{\circ} \mathrm{C}$, and alkaline property [Changlin Zhou, 2018; Aleksandar Nikolov 2017]. Its alkalinity nature of Portland cement makes it susceptible to attack acid [Attiogbe and Rizkalla, 1988]. As for the durability of concrete, it is much affected by sulfates, salt, acid solutions, freezing and thawing. [Changlin Zhou., 2019], where durability, workability, strength are the three main 
properties of concrete [Behnam Vakhshouri, 2015].

To know how acid attacks the concrete, it is necessary to identify the mechanism by which the reactions are made, where calcium hydroxide $(\mathrm{Ca}(\mathrm{OH}) 2)$ is a typically byproduct of process of cement hydration that can be expressed as equation (1) [Concrete $\mathrm{pH}$ Testing Problems and Solutions, 2015].

Calcium Silicate + Water $\rightarrow$ Calcium Silicate Hydrate

$(\mathrm{C}-\mathrm{S}-\mathrm{H})+$ Calcium Hydroxide $(\mathrm{Ca}(\mathrm{OH}) 2)$

$$
\cdots \cdot \operatorname{Eq}(1)
$$

The reaction between the portion of $\mathrm{Ca}(\mathrm{OH}) 2$ and an acid which yields a Calcium salt (highly solvable) this process is called acid attack, the simple reaction is presented in equation (2).

Acid + Calcium Hydroxide $\rightarrow$ Calcium Salt + Water

$$
\cdots \cdot \operatorname{Eq}(2)
$$

A more destructive situation of acid attack happens as soon as concrete is attacked by sulfuric acid. The Stages of $\mathrm{Ca}(\mathrm{OH}) 2$ dissolution are done in two ways. The first stage begins in the cement paste when the reaction of both acid and $\mathrm{Ca}(\mathrm{OH}) 2$. The second stage starts the reaction of $\mathrm{C}-\mathrm{S}-\mathrm{H}$ with acid, this stage will not occur until completely $\mathrm{Ca}(\mathrm{OH}) 2$ is consumed. The dissolution of the $\mathrm{C}-\mathrm{S}-\mathrm{H}$ in this case, serious structural deterioration can be caused to the concrete [Acid Attack Mechanism, 2017].

Many studies have been done over many years to investigate the effect of adding admixtures to increase the physical and mechanical properties of concrete [Alfoul. 2019]. But in the literature review here, it will focus on what materials are most effective on concrete erosion. A study conducted in 1988 by Attiogbe and Rizkalla pointed out that the effect of concentration ratios of different types of acid on the concrete properties is significant, where nitric, hydraulic, and sulfuric acids were used to examine the possibility of using acids in construction demolition. In 2005, both Kawai and Shinmi researched the use of acid in cement mixtures. In this study, the surface corrosion of the concrete was measured when exposed to SA, where concrete samples were submerged in several content of $\mathrm{SA}$, and then the thickness of the area corroded by SA were determine. Also, deteriorated concrete areas were investigates with an XRD. The results of this study presented that the proportion of concrete deterioration produced by SA attack mainly depends on the $\mathrm{pH}$ of SA solutions. As well, it also showed that the depth of the damaged concrete is somewhat proportional to the duration of exposure to SA attack. Another investigation about acid attack achieved by Barbhuiya and Kumala in 2017. Five concrete specimens were cast. The first specimen was a control blend with $100 \%$ OC. The other mixtures contained OC with a variable proportions of fly ash (FA) and ultra-fine of fly ash (UFFA). An examinations were performed to influence acid attack on the concrete behavior, where sulphuric and nitric acid were used. The tests showed that losses value of compressive strength concrete were the lowest in which $30 \%$ FA and $10 \%$ UFFA as replaced content of total cement. This modified concrete mixture also displayed the lowest loss of mass when exposed to such an acid attack. The results show that acid attacks led to a decrease of compressive strength of concrete and weight loss. A recent study completed in 2019 by Xujian Lin and others. They measured the surface corrosion of concrete samples under the influence of biosulfuric acid (BSA), they made a comparison between two types of concrete mixes, one alkaline active concrete (AAC) and the ordinary concrete (OC). Investigational results revealed that the thickness, hardness and permeability of the corrosion surface of OC are noticeably larger than AAC. Furthermore, the bacterial influence on corrosion surface of AAC is larger than that of OC. corrosion surface track of BSA smaller than that of OC. Consequently, the AAC has corrosion resistance to influence BSA higher than that of OC.

\section{RESEARCH OBJECTIVES}

With the frightening and unexpected masses of demolished buildings in the Arab region, the main challenge for engineers is to find new and innovative demolition techniques. In this study, a new techniques have been adapted to dismantle and destroy concrete structures by exposing them to quantities of chemical solutions. The following process was implemented to examine the effect of three types of acid attack on the concrete: Nitric, Sulfuric and Hydrochloric acids. First, measure the penetration of acid to the concrete using different concentrations of acid and the concrete. Second, determine the most destructive attack of the concrete among the above mentioned acid. Third, conclude the decrease of compression strength of concrete. It has been adopted to make holes in concrete cubes before submerging them with acid solutions.

\section{MATERIALS PROPERTIES AND PROCEDURES.}

The details of the material information, investigational program, examination procedures and apparatus have been provided in this study. And then analyze the results of the investigational program have been presented. For illustrate an influence of acid attack on concrete surface deterioration, weight loss, thickness change, the concrete samples are casted based on ASTM C39-05. The concentrations of acids that have been used in this study are shown below:

1. Hydrochloric Acid: $36 \%$.

2. Nitric Acid: 36,50 and $69 \%$.

3. Sulfuric Acid: $36,50,80$ and $99 \%$.

There are two types of acids that are available in the market, commercial grade and lab grade. In this study only commercial grade acids have been used even though the commercial grade acids have impurities. Where the total number of acids solutions were used are 8 solutions. The 
reasons for using commercial-grade acids are:

1. A realistic simulation of practical demolition is needed since the objective of this study is to use acids in demolition processes which require many liters of acids. Thus, it is not economical to use lab-grade acids.

2. Commercial-grade acids have slightly more impurities.

3. Lab-grade acids are used for laboratory experiments to pursue accurate and precise results.

Dilution of Acids. Different concentrations have been used to compare all acids at one possible concentration, for example: it was possible to have $36 \%$ concentration from the three acids. Volume dilution have been carried out to reduce the concentrated acids to get the desired concentrations by using the relation: $\mathrm{C} 1 \mathrm{~V} 1=\mathrm{C} 2 \mathrm{~V} 2$; where $\mathrm{C} 1$ : Concentration of stock solution; V1: Volume of stock solution needed to make the new solution.C2: Final concentration of new solution;V2: Volume of distilled water. All acids have been diluted with distilled water in the lab using the following equipment and apparatus: Pycnometer; Flask; Volumetric pipette with pump; Funnel; Beaker.

Concrete Cubes. The concrete cubes of (15 X 15 x $15 \mathrm{~cm})$ and $(10 \times 10 \times 10 \mathrm{~cm})$ are brought ready from Kingdom Concrete to have a more uniform concrete mix than a mix that can be prepared in the concrete laboratory. The concrete cubes have an average compressive strength at 7 day and 28 days of 25.5 MPa and 34.6 MPa, respectively. Table (1) below shows the compressive strength of 6 cubes at 7 and 28 days. While table (2) shows the characteristics of the hole in the cubes as shown in Figure (1) below.

Table 1: Average Compressive Strength

\begin{tabular}{|c|c|c|c|}
\hline \multicolumn{2}{|c|}{ At 7 Days Age } & \multicolumn{2}{c|}{ At 28 Days Age } \\
\hline $\begin{array}{c}\text { Cube } \\
\text { No. }\end{array}$ & $\begin{array}{c}\text { Compressive } \\
\text { Strength } \\
\text { (MPa) }\end{array}$ & $\begin{array}{c}\text { Cube } \\
\text { No. }\end{array}$ & $\begin{array}{c}\text { Compressive } \\
\text { Strength } \\
\text { (MPa) }\end{array}$ \\
\hline 1 & 25.1 & 1 & 34.5 \\
\hline 2 & 25.4 & 2 & 34.4 \\
\hline 3 & 25.2 & 3 & 33.9 \\
\hline Average & 25.2 & Average & 34.6 \\
\hline
\end{tabular}

Table 2: The Characteristics of the Hole.

\begin{tabular}{|c|c|c|}
\hline Depth & Area(Wall + Base) & Volume \\
\hline $7 \mathrm{~cm}$ & $23 \mathrm{~cm}^{2}$ & $5.5 \mathrm{~mL}$ \\
\hline
\end{tabular}

Prior to preparing the acid solutions, the concrete cubes are wet cured for 7 days. They are also taken out of water to dry for 7 days, they are dried to determine the penetration of acids inside the cubes. The $(15 \times 15 \times 15 \mathrm{~cm})$ cubes are also drilled using a drill press to have uniform holes figure (1). The drilling process starts with drilling using $6 \mathrm{~mm}$ bits, then, $8 \mathrm{~mm}$ bits and at the end $10 \mathrm{~mm}$ bits. Masonry bits are used in the process; Figure (2). Also, water is poured on the bits while drill not to overheat. The depth of the hole is $7 \mathrm{~cm}$ with a diameter of $1 \mathrm{~cm}$. The volume of the groove is $5.5 \mathrm{~cm} 3$. The characteristics of the hole are shown in the table (2), figure (2) and (3) show masonry drill bits and drilled cube.

Mortar Cubes. These cubes of (5 X 5 X 5 cm) have been prepared to measure the compressive strength after full submersion in acids for 1 hour time. The cubes had been wet cured for 7 days and then have been taken out to dry for 3 days. The mix design that is used in making the cubes is shows in the table (3). The water content of the mix design is $33 \%$ or $200 \mathrm{~mL}$ for each $600 \mathrm{~g}$ of sand and cement. Figure 4 shows a $(5 \times 5 \times 5 \mathrm{~cm})$ cube.

Penetration and Chemical Reaction Rate. To determine the penetration and chemical reaction rate by observation, all the solutions where ready to be poured in the holes using 2 cubes of concrete for each of the 8 solution which have different concentrations of acids. The volume of the hole is $5.5 \mathrm{~mL}$. However, only $3 \mathrm{~mL}$ of acid is poured in in the beginning to avoid spillage and splashing because the reaction between acid and concrete generate bubbles and vapors. When the reaction ends and concrete absorbs the acid, more acid is poured in. The volume of the poured-in acid is recorded every 30 minutes. $100 \mathrm{~mL}$ was the maximum volume to be poured in as an assumption. The test would be stopped when one of the acids reach $100 \mathrm{~mL}$. Afterwards, the cubes are broken using a compressive strength machine and a hammer to measure the penetration.

Compressive Strength of ( 5 X 5 X $5 \mathrm{~cm})$ - Mortar Cubes. After getting the results from the penetration and chemical reaction rate methods. It was found that Hydrochloric acid (36\% concentration) and Nitric acid (69\% concentration) are the most reactive acids with concrete. Thus, two cubes are submerged in each of the two acids for one hour. The mass of each cube is measured before and after submersion. Then, the compressive strength is measure by the compressive strength machine. The results are compared to the compressive strength of same cubes but without any chemical treatment.

\section{RESULTS, CALCULATIONS AND DISCUSSION.}

The rate of chemical reactions (represented by acids consumption by time) is not the same for the acids which they have different concentrations. The most reactive acids are Hydrochloric acid (HCL - 36\% concentration) and Nitric acid $\left(\mathrm{HNO}_{3}-69 \%\right.$ concentration) but Nitric acid is more corrosive and reactive since the concrete absorbed $100 \mathrm{~mL}$ in 330 minutes through a contact area of $23 \mathrm{~cm}^{2}$. Concrete absorbed and reacted with only $37 \mathrm{ml}$ of Hydrochloric acid. $27 \mathrm{~mL}$ for Nitric acid with a concentration of $36 \%$ and $21 \mathrm{~mL}$ for Nitric 
acid with a concentration of $50 \%$. The least reactive acid was the sulfuric acid since only $6 \mathrm{~mL}$ is poured in and surprisingly the reaction stopped after a few minutes. For the Sulfuric acid $\left(\mathrm{H}_{2} \mathrm{SO}_{4}\right)$ case, the concrete did not absorb or react with the acid in hole, the sulfuric acid was not even absorbed by the concrete after 24 hours. Table (4) shows the volume of acids that are poured in in 330 minutes. Figure (5) shows the relation between time and the reaction of rate in terms of acids consumptions for the all acids solutions.

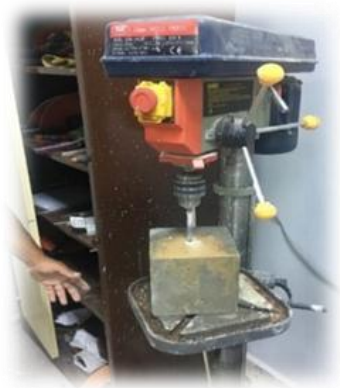

Fig. 1. Drill press

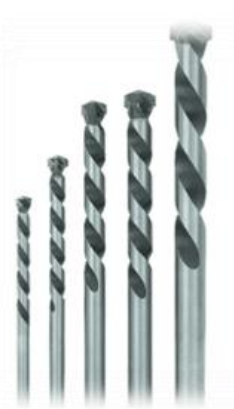

Fig. 2. Masonry drill bits

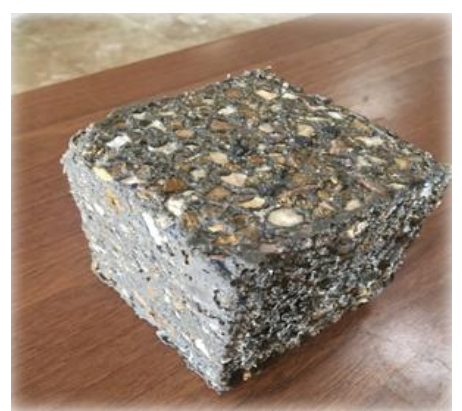

Fig. 5. 5 X 5 X $5 \mathrm{~cm}$ Mortar Cube after expose to acid

Table 3: Mortar Design Mix.

\begin{tabular}{|c|c|c|}
\hline Material & Cement & Sand \\
\hline Mass Percentage (\%) & 75 & 25 \\
\hline
\end{tabular}

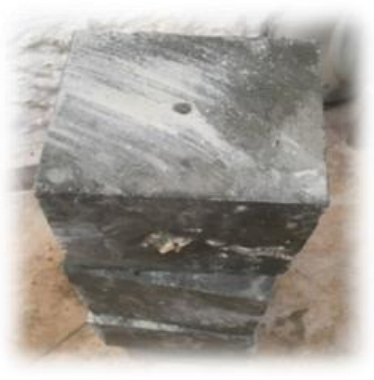

Fig. 3. Drilled Cube.

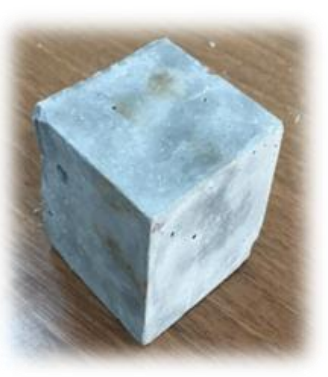

Fig. 4. 5X5X5 cm mortar

Table 4: Volume of Acids Poured In and the Rate of Reactions.

\begin{tabular}{|c|c|c|c|c|c|c|c|c|}
\hline \multirow{2}{*}{ Minutes } & \multicolumn{8}{|c|}{ Volume of Acids (mL) } \\
\hline & HCl $36 \%$ & $\mathrm{HNO}_{3} 36 \%$ & $\mathrm{H}_{2} \mathrm{SO}_{4} 36 \%$ & $\mathrm{HNO}_{3} \mathbf{5 0 \%}$ & $\mathrm{H}_{2} \mathrm{SO}_{4} 50 \%$ & $\mathrm{HNO}_{3} 69 \%$ & $\mathrm{H}_{2} \mathrm{SO}_{4} 80 \%$ & $\mathrm{H}_{2} \mathrm{SO}_{4} 99 \%$ \\
\hline $\mathbf{0}$ & 3 & 3 & 3 & 3 & 3 & 3 & 3 & 3 \\
\hline 30 & 6 & 6 & & 6 & & 6 & & \\
\hline 60 & 9 & 9 & & 9 & & 9 & & \\
\hline 90 & 12 & 12 & & 12 & & 15 & & \\
\hline 120 & 15 & 15 & & 15 & & 21 & & \\
\hline 150 & 18 & 18 & & 18 & & 28 & & \\
\hline 180 & 21 & 21 & & 21 & & 36 & & \\
\hline 210 & 25 & 24 & & & & 45 & & \\
\hline 240 & 31 & 27 & & & & 60 & & \\
\hline 270 & 37 & & & & & 78 & & \\
\hline 300 & & & & & & 90 & & \\
\hline 330 & & & & & & 100 & & \\
\hline
\end{tabular}


As shown in Fig. 6, the reaction rate of Nitric acid $(69 \%$ concentration) is faster because of its corrosive nature. For instance, at 240 minutes, the concrete reacted with $60 \mathrm{~mL}$ of Nitric acid (69\% concentration) while only with $27 \mathrm{~mL}$ of Hydrochloric acid (36\% concentration) after which the reaction stopped. It is very important to know that the concrete was able to react and absorb more Nitric acid (69\% concentration) but $100 \mathrm{~mL}$ was the maximum volume for this methodology.

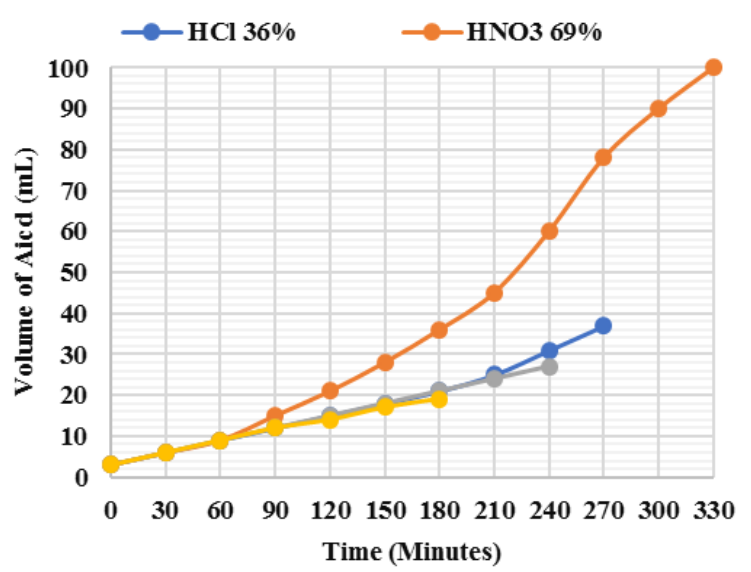

Fig. 6. Relation between time and acids volumes consumed (reaction rate) - $\left(\mathrm{HCL} 36 \%, \mathrm{HNO}_{3} 69 \%, \mathrm{HNO}_{3} 36 \%\right.$ and $\mathrm{HNO}_{3} 50 \%$ ).

Penetration. The penetration is measured after breaking the cubes by the compressive strength machine, the cubes are furthermore broken by a hammer into smaller particles to measure the penetration. The penetration for Nitric acid $(69 \%$ concentration) and Hydrochloric acid (36\% concentration) is the same and almost unformed along the depth and around circumference of the cube. The Penetration for the Hydrochloric acid ( $36 \%$ concentration) is $1 \mathrm{~cm}$ and the same amount for Nitric acid (69\% concentration). However, for Nitric acid (69\% concentration) case the hole got wide the diameter which was increased to be $1.25 \mathrm{~cm}$ and the depth increased to $7.8 \mathrm{~cm}$. Figure 7 is illustrated the penetration in inside the tested cubes.

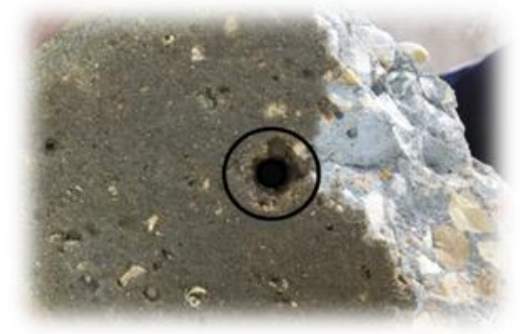

Fig 7. Penetration of Nitric acid (69\% concentration).

Compressive Strength of $5 \mathrm{~cm}$ X $5 \mathrm{~cm}$ Mortar Cubes. The submersed mortar cubes in acids (Hydrochloric and Nitric) resulted a reduction in mass and compressive strength. After full submersion of cubes in $300 \mathrm{~mL}$ of Hydrochloric $(36 \%$ concentration) acid for 1 hour, the compressive strength reduced by $26.5 \%$ on average for samples No. $3 \& 4$. Moreover, the average reduction in mass is $19.4 \%$. For Nitric acid (69\% concentration), the chemical attack reduced the compression strength by $37 \%$ for samples No. $5 \& 6$, and the mass reduction is $21 \%$. Tables 5, 6, 7, 8 and 9 summarized these results.

Table 5. Compressive Strength of Mortar Cubes

\begin{tabular}{|c|c|}
\hline Sample No. & $\begin{array}{c}\text { Original Compressive } \\
\text { Strength }(\mathrm{MPa})\end{array}$ \\
\hline 1 & 22.64 \\
\hline 2 & 23.04 \\
\hline Average & 22.84 \\
\hline
\end{tabular}

Table 6. Compressive Strength of Mortar Cubes

\begin{tabular}{|c|c|}
\hline Sample No. & $\begin{array}{l}\text { Compressive } \\
\text { Submersing in } \mathrm{HCl}(36 \%) \\
(\mathrm{MPa})\end{array}$ \\
\hline 3 & 17.17 \\
\hline 4 & 16.35 \\
\hline Average & 16.76 \\
\hline
\end{tabular}

Table 7. Compressive Strength of Mortar Cubes after

\begin{tabular}{|c|c|}
\hline Sample No. & $\begin{array}{c}\text { Compressive } \\
\text { Submersing in } \mathrm{HNO}_{3}(69 \%)(\mathrm{MPa})\end{array}$ \\
\hline 5 & 14.46 \\
\hline 6 & 14.25 \\
\hline Average & 14.35 \\
\hline
\end{tabular}

Table 8. Reduction in Compressive Strength after Submersion

\begin{tabular}{|c|c|c|}
\hline $\begin{array}{c}\text { Average } \\
\text { Compressive } \\
\text { Strength }\end{array}$ & $\begin{array}{c}\text { Average } \\
\text { Compressive } \\
\text { Strength After } \\
\text { Submersing in } \mathrm{HCl}\end{array}$ & $\begin{array}{c}\text { Average } \\
\text { Compressive } \\
\text { Strength After } \\
\text { Submersing in } \\
\text { HNO3 }(69 \%)\end{array}$ \\
\hline 22.84 & $16 \%)(\mathrm{MPa})$ & 14.35 \\
\hline
\end{tabular}

Figures 8 and 9, show a visual illustration of the average compressive strength ( $\mathrm{MPa})$ for the ordinary sample and those submersed with HCL $36 \%$ and HNO3 $69 \%$ before and after the tests. It is clear from figures that the average compressive strengths are decreased from the $22.84 \mathrm{MPa}$ for original sample comparing to 16.76 and $14.35 \mathrm{MPa}$ in cases of the submersions of the samples in $\mathrm{HCL} 36 \%$ and $\mathrm{HNO}_{3} 60 \%$ acids, respectively. 


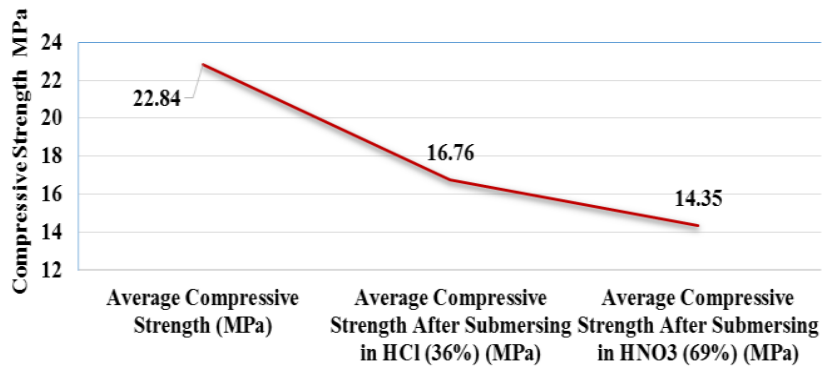

Fig. 8. Visual Illustration of Compressive Strength Reduction

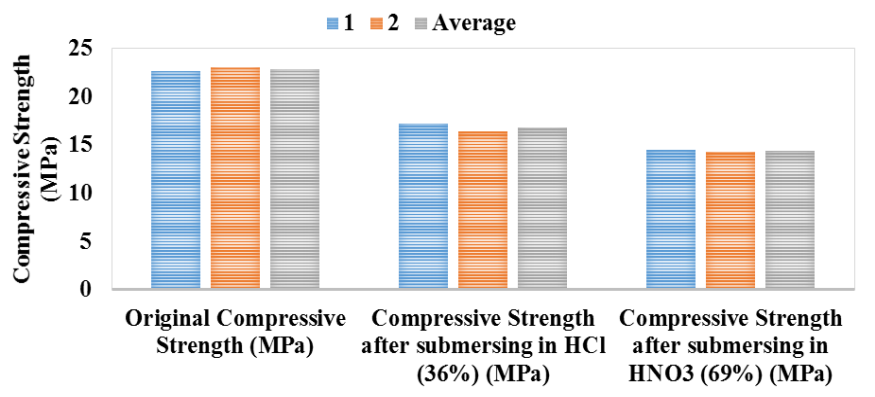

Fig. 9. Visual Illustration of Compressive Strength Before and After Submersion

Table 9. Compressive Strength Before and After Submersion

\begin{tabular}{|c|c|c|c|c|c|}
\hline Sample No. & Original Mass $(\mathrm{g})$ & $\begin{array}{c}\text { Mass after submersing in } \\
\mathrm{HCl}(36 \%)(\mathrm{g})\end{array}$ & Sample No. & $\begin{array}{c}\text { Original } \\
\text { Mass }(\mathrm{g})\end{array}$ & $\begin{array}{c}\text { Mass after submersing in } \\
\mathrm{HNO}(69 \%)(\mathrm{g})\end{array}$ \\
\hline 1 & 237.6 & 189.3 & 1 & 239.6 & 187.9 \\
\hline 2 & 231.2 & 188.7 & 2 & 232.4 & 185.3 \\
\hline Average & 234.4 & 189.0 & Average & 235.9 & 186.6 \\
\hline Reduction & & $19.4 \%$ & Reduction & & $21.0 \%$ \\
\hline
\end{tabular}

For one hour of immersion, Nitric acid (69\% concentration) resulted more reduction mass than the Hydrochloric acid (36\% concentration) which comply with the results of table 4 , that shows for the same time elapsed for Nitric acid $(69 \%$ concentration) which has a more reaction rate than the Hydrochloric acid (36\% concentration). Therefore, Nitric acid (69\% concentration) has a bigger reduction of compressive strength. These effect leads that the samples loss of their mass. Figures 10 and 11 below show the mass reductions of the samples tested by using Hydrochloric acid (36\%) and Nitric acid $(69 \%)$. It is clear that there is big difference between the mass lost in case of Hydrochloric acid (36\% concentration) with the case of using Nitric acid of ( $69 \%$ concentration).

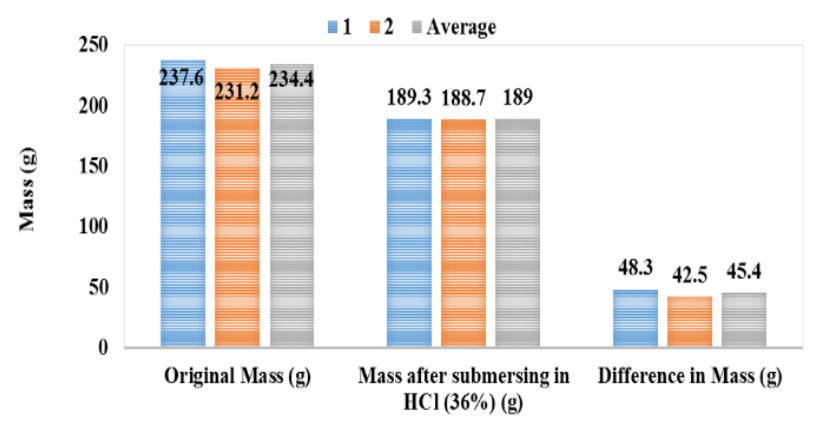

Fig.10. Visual Illustration of Masses Before and After Submersion in Hydrochloric Acid (36\%).

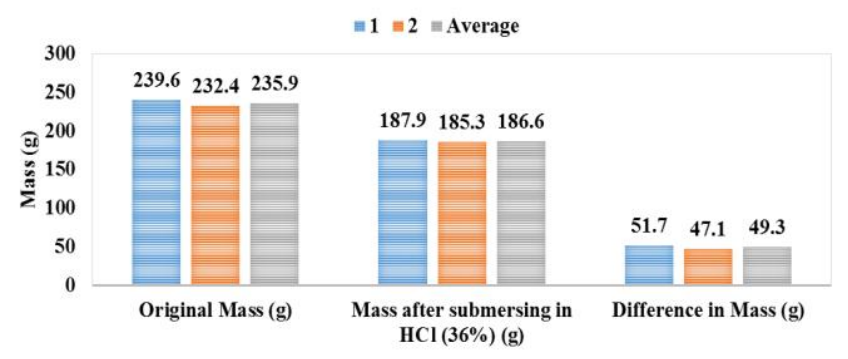

Fig. 11. Masses Before and After Submersion in Nitric Acid $(69 \%)$.

\section{CONCLUSION}

This research was carried out to illustrate the effect of the attack of acid types on the concrete properties as well as the definition of the rate of chemical reactions, amount of absorption of the concrete, penetration that occurs as a result of that effect and the concentration of acid solution required. This study gave a set of results and conclusions which can be summarized by the followings; (1) The rate of chemical reactions is not the same for the acids which they have different concentrations. The Nitric acid is more corrosive and reactive since the concrete absorbed $100 \mathrm{~mL}$ in 330 minutes through a contact area of $23 \mathrm{~cm} 2$. The least reactive acid was the sulfuric acid since only $6 \mathrm{~mL}$ is poured in and surprisingly $\begin{array}{ll}\text { the reaction stopped after a few minutes. } & \text { (2) The }\end{array}$ penetration in the sample for the Hydrochloric acid (36\% concentration) is $1 \mathrm{~cm}$ and the same depth was obtained in case of Nitric acid (69\% concentration). However, for Nitric acid $(69 \%$ concentration) case the hole got wide the diameter 
which was increased to be $1.25 \mathrm{~cm}$ and the depth increased to $7.8 \mathrm{~cm}$. (3) After full submersion of cubes in $300 \mathrm{~mL}$ of Hydrochloric (36\% concentration) acid for 1 hour, the compressive strength reduced by $26.5 \%$ on average, the average reduction in mass is $19.4 \%$. (4) For Nitric acid $(69 \%$ concentration), the chemical attack reduced the compression strength by $37 \%$ for samples No. $5 \& 6$, and the mass reduction is $21 \%$.

\section{ACKNOWLEDGEMENTS}

The authors are thankful to the Middle East University, Amman, Jordan for the financial support granted to cover the publication fee of this research article.

\section{REFERENCES}

[1] AAZDAK, A, 2008. Demolition-There are many different variations. Retrieved from. http://EzineArticles.com/?expert=Aazdak_Alisimo Accessed 8/10/2019.

[2] Acid Attack - Mechanism (2017) Retrieved from http://www.engr.psu.edu/ce/courses/ce584/concrete/libr ary/chemical/chemframe.html.

[3] Aleksandar Nikolova, $\square$, Ivan Rostovskya, Henk Nugterenb. 2017. Geopolymer materials based on natural zeolite. Case Studies in Construction Materials. http://dx.doi.org/10.1016/j.cscm.2017.03.001.

[4] Anumba, Chimay. Abdullah, Arham. Fesseha, Tewedros. 2003. Selection of demolition techniques: a case study of the Warren Farm Bridge, Structural Survey, Vol. 21 Issue: 1, pp.36-48, doi: 10.1108/02630800310470853.

[5] Attiogbe, Emmanuel K., and Sami H. Rizkalla, 1988 "Response of concrete to sulfuric acid attack." ACI Materials Journal 85.6 (1988): 481-488.

[6] Aymen Awad, 2020. "Guidelines for Civil Structures Demolition Method Selection to Enhance Environmental Protection". International Journal of Emerging Trends in Engineering Research (IJETER), Volume-8 Issue-2, February 2020.

[7] Behnam Vakhshouri, Shami Nejadi, 2015. Mix design of light-weight self-compacting concrete. Case Studies in Construction Materials. http://dx.doi.org/10.1016/j.cscm.2015.10.002.

[8] Bilal Abu Alfoul*, Omar Al Hattamleh, Hussein Aldeeky, 2019. Investigating the effects of disc shaped thumb tacks as a "fiber" reinforcement on various concrete properties. Case Studies in Construction Materials. https://doi.org/10.1016/j.cscm.2019.e00257.

[9] Changlin Zhou, Zheming Zhu 爪, Zhihong Wang, Hao Qiu, 2018. Deterioration of concrete fracture toughness and elastic modulus under simulated acid-sulfate environment. Case Studies in Construction Materials. https://doi.org/10.1016/j.conbuildmat.2018.05.049.
[10] Concrete pH Testing Problems and Solutions. 2015, June $24 . \quad$ Retrieved from: https://www.stoversliquidation.com/blog/concrete-phtesting-problems-and-olutions/

[11] Demolition - Best practice guidelines for demolition in New Zealand (DBPGDNZ). https://miningquiz.com/pdf/Welding/appendix-gsample-hot-work-permit.pdf. Accessed 8/10/2019.

[12] Diane Gardner, Robert Lark, Tony Jefferson, Robert Davies, 2018. A survey on problems encountered in current concrete construction and the potential benefits of self-healing cementitious materials. Case Studies in Construction Materials. ttps://doi.org/10.1016/j.cscm.2018.02.002.

[13] Doha M. Al Saffar, Aymen J.K. Al Saad, Bassam A. Tayeh, 2019. Effect of internal curing on behavior of high performance concrete: An overview. Case Studies in Construction Materials. https://doi.org/10.1016/j.cscm.2019.e00229.

[14] G. Bradley Guy, Timothy J, 2018. Powell Center for Construction and Environment, University of Florida, Gainesville, FL 32611- 5703. Accessed 8/10/2019.

[15] K. Kawai, S. Yamaji, T. Shinmi, 2005. Concrete Deterioration Caused by Sulfuric Acid Attack. 10DBMC International Conference On Durability of Building Materials and Components LYON [France] 17-20.

[16] Mahdi Koushkbaghi, Mahyar Jafar Kazemi, Hossein Mosavi, Ehsan Mohseni, 2019. Acid resistance and durability properties of steel fiber-reinforced concrete incorporating rice husk ash and recycled aggregate. Construction and Building Materials. https://doi.org/10.1016/j.conbuildmat.2018.12.224.

[17] Najib N. Gergesa, Camille . Issab, Samer. Fawazb. Rubber concrete: Mechanical and dynamical properties. Case Studies in Construction Materials.https://doi.org/10.1016/j.cscm.2018.e00184.

[18] Olaniyi Arowojolu, Ebenezer Fanijo, Ahmed Ibrahim, 2019. Behavior of kernelrazzo floor finish in aggressive chloride environment. Case Studies in Construction Materials. https://doi.org/10.1016/j.cscm.2019.e00256.

[19] PCA, Types and Causes of Concrete Deterioration, Portland Cement Association, Skokie, Illinois, 2002, 16 pages.

[20] Pranav, Patel. Pitroda, Jayeshkumar. Bhavsar, J.J. 2015 .Demolition: Methods and Comparison. Retrieved from: file:///D:/Ali/Downloads/15CE020\%20PNP-JRPJB\%20DEMOLITION\%20METHODS\%2011-032015.pdfFa.

[21] Saleh A. Al-Saleh, 2015. Analysis of total chloride content in concrete. Case Studies in Construction Materials. http://dx.doi.org/10.1016/j.cscm.2015.06.001.

[22] Salim Barbhuiya and Davin Kumala, 2017. Behaviour 
of a Sustainable Concrete in Acidic Environment. www.mdpi.com/journal/sustainability.

[23] Sallal R. Abida, Ali H. Nahhabb, Husam K.H. Alaayedia, Athraa M. Nuhair, 2018. Expansion and strength properties of concrete containing contaminated recycled concrete aggregate. Case Studies in Construction Materials https://doi.org/10.1016/j.cscm.2018.e00201.

[24] Schultmann, F, 2018. 15 Sustainable deconstruction of buildings. Smart and Sustainable Built Environments, pp, 148-149.

[25] Usman, Nuruddeen, and Ilias Said. 2012. An evaluation of buildings destruction technique and its menace. European Journal of Scientific Research 74.1 (2012): 134-142.

[26] Yudong Xie, Xujian Lin $\Uparrow$, Tao Ji, Yongning Liang, Weijie Pan. 2019. Comparison of corrosion resistance mechanism between ordinary Portland concrete and alkali-activated concrete subjected to biogenic sulfuric acid attack. Case Studies in Construction Materials. https://doi.org/10.1016/j.conbuildmat.2019.117071.

[27] Al Adday, F. (2019). Fresh and hardened properties of recycled concrete aggregate modified by iron powder and silica. International Journal of GEOMATE, 16(53), 222-230. https://doi.org/10.21660/2019.53.96609

[28] Al Adday, F. (2020). Investigational Assessment of Modified Performance of Used Tire Concrete Mixtures. International Journal of Emerging Trends in Engineering Research, 8(5), 1804-1808. https://doi.org/10.30534/ijeter/2020/52852020

[29] Al Adday, F., \& Awad, A. (2019). Pre-wetting of recycled concrete as alternative of chemical, natural and industrial waste additives. International Journal of Innovative Technology and Exploring Engineering, 8(12), 743-748. https://doi.org/10.35940/ijitee.L3166.1081219

[30] Fatima Alsaleh, F. A. A. (2019). Manufacture of Lightweight Thermal Insulation Concrete Using Recycled Aggregates and Syrian Pozzolan. International Journal of Advanced Trends in Computer Science and Engineering, 8(3), 959-962. https://doi.org/10.30534/ijatcse/2019/96832019 